\title{
Comparison of Health-Related Physical Fitness Levels of Girls in Day and Boarding Senior High Schools in Cape Coast
}

\author{
Charity Nordzro, Richmond Stephen Sorkpor, Bismark Tsorhe \\ Aggrey Senior High School, Cape Coast, Ghana \\ Tutor, OLA College of Education, Cape Coast, Ghana. \\ Tutor, St Teresa's College of Education, Hohoe, Ghana.
}

\begin{abstract}
The purpose of the study was to find out any differences in the health-related physical fitness levels of day and boarding girls in the SHS in Cape Coast, Ghana. The study employed the descriptive survey design involving One hundred and sixty (160) respondents who are SHS girls from Aggrey Memorial Senior High School and Ghana National College were used for the study. The Prudential Fitnessgram (2002) battery of tests was used to test the five components of health-related physical fitness of each subject for the study. The scores were processed and analyzed using the independent samples t-test and the Healthy Fitness Zone (HFZ). From the HFZ values and the t-test statistics results, there is an indication that the boarding girls were at higher risk in respect to the health related physical fitness components tested. The day girls were fitter in all the five health-related physical fitness components tested. This may be due to the fact that the nature and intensity levels of physical activities differ between the two groups. The comparatively poor health-related physical fitness condition of the girls in the boarding house is not good at all and needs an urgent, practical and comprehensive approach to deal with it, such as designing physical education, sporting and recreational activities to be interesting and attractive for students to participate.
\end{abstract}

Key Words: Physical Fitness, Body composition, Cardiovascular Endurance

\section{Introduction}

For some time now there has been an increase in the awareness of being physically fit as a positive health habit that has a major impact on the wellness of every individual. There is now strong scientific evidence linking physical fitness, not only to better health but also to decreased medical cost, improved academic work and improved job productivity (Robins, Powers \& Burgess, 1994).

In recent times, the awareness to be fit or to stay healthy in order to enjoy a meaningful life has been the concern of the young and old as well as the Government of Ghana. The need to increase physical fitness through healthy lifestyle is of paramount importance to most people in the urban communities. This accounts for the coming up of so many keep fitness programmes in the cities. Physical fitness is a general concept with two specific components being the health-related physical fitness and the motor-related physical fitness. This study however is concerned with the health-related physical fitness levels of day and boarding girls in SHS in Cape Coast. Health-related physical fitness is defined by Corbin, Lindsey, Welk \& Corbin (2002) as the body's ability to function efficiently and effectively without undue fatigue, and to enjoy leisure time, be healthy, resist hypokinetic diseases and meet emergency situations.

Health-related physical fitness activities are gradually gaining root in the Ghanaian society as part of healthy living. The Ghana Health Service (GHS) of the Ministry of Health (MOH) has committed itself to helping people improve their health status in the country through comprehensive health promotion and disease prevention like educating the populace on the need to take part in keep fit programmes, cut down on fatty foods, eat healthy and balanced diet and do more physical activities. In the public health centres, programmes emphasized disease prevention, health promotion, and not treatment of disease alone (Akorsah, 
2006). With this idea, the GHS wants to help individuals to lead healthier lives that will help them to live long, improve the health and the fitness status of the nation's children, youth, and the aged, and reduce the disparities in health status among different population groups.

Apart from the GHS, the Ghana Education Service (GES) has also outlined comprehensive programmes in the teaching of physical education (P.E.) and sporting activities (from inter-house to regional games) to help improve the health of students. At a recently held super-zonal competition on the schools and colleges field at Adisadel College in 2007, The Central Regional Minister, Mr. Isaac Edumadzi made mention of the fact that students who take part in physical activities hardly fall sick. He emphasized fitness as a basis for good health and excellence in academic work in schools in the country.

For individuals to be healthy, they must commit themselves to physical dimensions of health, which deals with the functional operation of the body; in other words, is your body the best machine possible? The physical dimension involves the health-related components of physical fitness which are cardiovascular endurance, muscular strengths, muscular endurance, flexibility and body composition. It also includes medical self-care, regular self-tests, check-ups, and proper use of medications.

Bucher and Prentice (1985) defined physical fitness as the capacity of the heart, lungs, blood vessels and muscles to function at optimal efficiency. The fit individual is able to complete the normal routine for the day and still have ample reserve energy to meet the other demands of daily recreational sports, rewarding relationships, and other leisure activities. Also, the fit individual has adequate energy to handle life's emergency or crisis situations whenever they arrive.

Blair, as cited in Robbins et al. (1994) has said that a sedentary lifestyle is a risk factor for diseases such as high blood pressure and obesity. Boateng a renowned Ghanaian Heart Surgeon has during a GTV interview in 2006 to celebrate world heart day said that the sedentary life style of present day youth has resulted in the high rate of hypokinetic diseases among students' girls in our SHS in Ghana.

The growing interest of SHS boys in sporting activities has made them more physically active than their female counterparts, especially the SHS girls who stay away from active sports due to fear of becoming muscular, and other misconceptions. The lack of vigorous physical activities in the lifestyle of the girls in SHS might be the reason for the generally accepted low levels of cardiovascular endurance, muscular strength, muscular endurance, flexibility and body composition which are the main component of the healthrelated physical fitness.

\section{Statement of the Problem}

The frequent report of sickness by the SHS boarding girls has gradually become a problem of discussion during staff meetings. From the beginning of the term there is not a single day that a student is not found at the sick bay or being referred to general hospitals in Cape Coast. This is not a peculiar problem to a school but a common problem that has developed among the SHS with boarding girls. Hardly would you see a day girl at the sick bay or being referred to the hospital. The frequent visits of the boarding girls to the sick bay and the hospitals go a long way to affect their academic work and also put unnecessary pressure on the housemistresses that have to stop teaching and to accompany them to the hospitals. The cause of the frequent sickness of the boarding girls could be attributed to their health-related physical fitness levels. The general lifestyle of the SHS day girls which involve walking longer distances to school and home coupled with other physical activities at home seem to improve their health-related physical fitness levels which might account for their not reporting frequently to the sick bay and to the hospital. This trend of events motivated the current research.

\section{Purpose of the Study}

The purpose of the study was to find out whether there existed any differences in the health-related physical fitness levels of day and boarding SHS girls in Cape Coast.

\section{Research Questions}

1. What is the difference in cardiovascular endurance levels between day and boarding SHS girls in Cape Coast? 
2. What is the difference in muscular endurance levels between day and boarding SHS girls in Cape Coast?

3. What is the difference in muscular levels between day and boarding SHS girls in Cape Coast?

4. What is the difference in flexibility levels between day and boarding SHS girls in Cape Coast?

5. What is the difference in body composition levels between day and boarding SHS girls in Cape Coast?

\section{Methodology}

The study was, therefore, structured within the framework of descriptive survey research. A total of 160 subjects were selected using simple random sampling method for the study. 100 student girls were selected from Aggrey, comprising of 80 boarding girls and 20 day girls, whiles the 60 students selected from Ghana National College were made up of 40 boarding girls and 20 day girls. This is so, because the population of Aggrey Memorial is higher than that of Ghana National College. The instrument for the study was the Prundential Fitnessgram (2002) which was designed by the Cooper Institute for Aerobic Research in Dallas in the United States of America (USA). The instrument has widely been used in the USA and Europe and has proved to be a reliable instrument in the evaluation of students' status relative to the different healthrelated fitness components.

\section{Results/Discussion}

Question 1: What is the Difference in Cardiovascular Endurance levels between Girls of Day and Boarding SHS in Cape Coast?

Table 1 shows the descriptive statistics of the day and boarding girls. The mean score of the day girls is slightly higher than that of the boarding girls in terms of their cardio-vascular endurance performance.

Table 1: Independent Samples t-test Result of Cardiovascular Endurance Fitness Levels for Day and Boarding girls

\begin{tabular}{|l|l|l|l|l|l|l|l|}
\hline Group & $\mathrm{N}$ & $\mathrm{M}$ & $\mathrm{SD}$ & $\mathrm{SE}$ & $\mathrm{df}$ & $\mathrm{t}$ & Sig. \\
\hline Day & 40 & 52.63 & 10.89 & 1.72 & 158 & 3.13 & $0.00(\mathrm{~S})$ \\
\hline Boarders & 120 & 47.53 & 8.14 & 0.74 & & & \\
\hline \multicolumn{7}{c|}{$\mathrm{S}=$ Significant } \\
\hline
\end{tabular}

The independent sample t-test showed that there was a significant difference between the cardiovascular endurance fitness levels between day and boarding girls in Cape Coast. The day girls were stronger and healthier in the cardio-vascular endurance fitness levels more than their boarding counterparts.

Sub-question 1 was also tested with the HFZ percentage analysis and the results are presented below in Table 2.

Table 2: HFZ Percentage Analysis of Fitnessgram Measurement of Cardiovascular Endurance

\begin{tabular}{|l|l|l|l|l|}
\hline HFZ & Day & Girls & Boarding & Girls \\
\hline & $\mathrm{n}$ & $\%$ & $\mathrm{~N}$ & $\%$ \\
\hline High performance & 36 & 90 & 69 & 57 \\
\hline Good fitness zone & 4 & 10 & 31 & 26 \\
\hline Marginal & 0 & 0 & 14 & 12 \\
\hline Need improvement & 0 & 0 & 6 & 5 \\
\hline Total & 40 & 100 & 120 & 100 \\
\hline
\end{tabular}

The results in the table 2 showed that the day girls were healthier and fitter than the boarding girls. From the table as high as $100 \%$ of the day girls that were selected for the study fell with high performance and good fitness zone without any falling within the marginal and Need Improvement zones, while 57.5\% and 25.83\% of the boarding girls fell within the high performance and good fitness zones, as much as $11.67 \%$ and $5 \%$ fell within the marginal and need improvement zones respectively. It showed that more boarding girls showed more weakness in cardiovascular endurance and needed to involve themselves in more physical activities to improve their cardiovascular endurance level. The HFZ percentage analysis of the 1,600 metres run/walk test confirmed sub-hypothesis 1. 
The reason for the higher cardiovascular endurance level of the day girls may be due to the fact that the day girls engage in more physical activities than the boarding girls. They do more walking over distances to school and back, do more home chores like walking distances to fetch water, cook, wash, sweep and a whole lot of home chores which are good physical activities as compared to their boarding counterparts who have everything done for them by the pantry women. David (1986) states that in a study, a group of students walked on a treadmill for 40 minutes four times a week. At the end of 20 weeks, their $\mathrm{VO}_{2} \mathrm{max}$ had increased by $28 \%$ and their heart rates during exercise had increased anywhere from 4 to 17 beats per minute. The walkers also showed improved lung capacity and a drop in body fat. In addition to its fitness benefits, walking is simple, safe and accessible to nearly everyone, all of which increase the chances of someone sticking with a regimen. Physical activity and health report of the American Surgeon General (2000) emphatically states that regular physical activity preferably performed daily will reduce one's risk of developing or dying from heart-related disease. Regular and vigorous physical activity increases muscle size, strength and power and develop endurance for sustaining work, and taxes the circulatory and respiratory systems. Vigorous daily activity positively develops cardiovascular fitness that produces the quality of physical reserve, power and stamina-endurance.

The higher $\mathrm{VO}_{2}$ max mean may also be as a result of a better engagement in vigorous physical activities like aerobics. This may fall in line with the findings of Laliberte (2001) which states that the better the running times, the better the aerobic capacity. The higher cardiovascular endurance could also be explained by the statistically significant difference in muscular endurance to the advantage of the day girls. According to experts, weight training for strength can stimulate the cardiovascular system (Lumpkin, 2002).

Inadequate physical activities in SHS campuses are putting the students in a sedentary way of life more especially in a situation where they engage in physical education once every week within 80 minute. It is not every girl that takes part in the physical education once a week. A sedentary lifestyle is one of the six major risk factors for cardiovascular endurance diseases (CVD). People who are sedentary have CVD death rate significantly higher than those of fit individuals. Cardiovascular disease usually begins to develop in childhood and adolescence; it progresses slowly over many years before producing any symptoms. Adopting healthy habit while young can help many people prevent or delay a heart attack or other serious forms of CVD (Insel and Roth, 2002). Blair, an epidemiologist for the Cooper Institute for Aerobics Research as cited in Robbins et al. (1997) as said that sedentary lifestyle is as much a risk factor for disease as is high blood pressure and obesity.

Sedentary living, experts warn, leads to coronary artery disease and perhaps to some cancers, stroke, noninsulin dependent diabetes mellitus and other health problems. As the boarding girls do not engage in any physical and other related activities, their aerobics capacity which is considered to be the best indicator of cardiovascular fitness diminishes. This happens because aerobic physical activities are the only means to achieve it (Corbin et al. 2002).

Another contributing factor that will not motivate the boarding girls to engage in physical activities on campuses may be the heavy academic work load. They may feel they will be wasting their time on any physical activities that is not examinable at the end of the day, without thinking of the effect on their health.

Sub-hypothesis 2: What is the Difference in Muscular Endurance Fitness Levels between Day and Boarding Girls in Cape Coast?

The independent samples t-test result of muscular endurance (curl-ups) test for day and boarding girls are presented on table 3.

Table 3: Independent Samples t-test Result of Muscular Endurance (Curl-ups) Test for Day and Boarding Girls

\begin{tabular}{|l|l|l|l|l|l|l|l|}
\hline Group & $\mathrm{N}$ & $\mathrm{M}$ & SD & SE & df & t & Sig. \\
\hline Day & 40 & 25.75 & 3.65 & 0.58 & 158 & 2.70 & $0.01(\mathrm{~S})$ \\
\hline Boarders & 120 & 23.77 & 4.14 & 0.38 & & & \\
\hline \multicolumn{7}{c}{ S = Significant } \\
\hline
\end{tabular}


The independent samples t-test revealed that there was a significant difference in muscular endurance levels of the day and boarding girls sampled for the study. The finding therefore confirmed the sub-hypothesis 2 and also responded positively to research question 2 .

The results presented in table 3 confirmed the assumed sub-hypothesis 2 which states that there is a significant difference between day and boarding girls in SHS in muscular endurance of which the day girls did better than the boarding girls. The difference is important due to the fact that the p-value which is the significant level is less than the alpha-level of 0.05 .

Table 4 also depicts the analysis on HFZ of the curl-ups test results used to measure the muscular endurance levels of the students for the study.

Table 4: HFZ Performance Analysis of Fitnessgram Measurement of Muscular Endurance (Curl-ups) Test

\begin{tabular}{|l|l|l|l|l|}
\hline HFZ & Day & Girls & Boarding & Girls \\
\hline & $\mathrm{n}$ & $\%$ & $\mathrm{~N}$ & $\%$ \\
\hline High performance & 7 & 17 & 13 & 11 \\
\hline Good fitness zone & 32 & 80 & 84 & 70 \\
\hline Marginal & 1 & 3 & 23 & 19 \\
\hline Need improvement & 0 & 0 & 0 & 0 \\
\hline Total & 40 & 100 & 120 & 100 \\
\hline
\end{tabular}

From table 4, it indicates that there was a significant difference in the percentage attainment for High Performance and Good Fitness Zone for the day and boarding girls in respect of the curl-ups. The day girls as usual had percentages in both zones at $17 \%$ and $80 \%$, higher than the boarding girls who had $11 \%$ and $70 \%$, respectively. The differences in the percentages indicate that the day girls are still fitter when it comes to muscular endurance. In the Marginal zone, whilst the day girls had only $3 \%$ falling in the zone, the boarding girls had as high as $19 \%$, showing that the day girls are fitter than the boarding girls. For the need improvement none of the day and boarding girls fell within.

The results show that although the day girls are healthier in terms of the muscular endurance, the boarding girls also showed some strength. The findings on the muscular endurance proved that there was statistically significant difference between the day and the boarding girls.

The advantage of the day girls over the boarding girls in muscular endurance may be due to the home chores they engage in that have been mentioned earlier, like walking distances to school, walking distances to fetch water, sweeping, helping to cook at home, and washing the family's clothing's at the weekend. A person with a moderate-to-high level of muscular endurance can perform everyday task imposed on him. This is what Fahey, Insel and Roth, (2002) has said. Most of the day girls do stay on their own and do stay in town as long as they can and are sometimes faced with challenges of running for their lives.

Again, most of the day girls are involved in the small basketball teams and soccer teams which are springing up all over in the Cape Coast vicinity which can also boast their endurance level. All these physical activities may be a contributing factor to the improved muscular endurance of the day girls. This may explain the significant difference of the muscular endurance between the day girls over the boarding girls sampled for the study. Unlike the day girls who choose the food they eat and all other activities which can improve their muscular endurance level, every activity the boarding girls engage in is determined by the authorities of the schools which may not be physically oriented and can be the reason for poor muscular endurance level. The boarding girls do not engage in physical activities like walking distances to fetch water, washing of clothing, walking distances to school, weeding and other home chores that the day girls engage in. sweeping and other physical works on campus are done by the form one students. 
Sub-Question 3: What is the difference in Muscular Strength levels between day and boarding SHS Girls in Cape Coast?

To test for the authenticity of sub-hypothesis three (3), again the t-statistics was employed, and the result is presented in Table 5.

Table 5: Independent Samples t-test Result of Muscular Strength Test for Day and Boarding Girls

\begin{tabular}{|l|l|l|l|l|l|l|l|}
\hline Group & $\mathrm{N}$ & $\mathrm{M}$ & $\mathrm{SD}$ & SE & Df & t & Sig. \\
\hline Day & 40 & 25.95 & 2.57 & 0.41 & 158 & 2.33 & $0.02(\mathrm{~S})$ \\
\hline Boarders & 120 & 24.72 & 3.00 & 0.27 & & & \\
\hline
\end{tabular}

From the table 5, it is evident that the assertion stated in the hypothesis is true. Comparing the p-value of 0.02 and the alpha level of 0.05 a decision could be made that, "since the p-value is less than the alpha level we reject the null hypothesis, in this context we accept the sub-question that 'there is a significant difference in muscular strength levels between day and boarding girls in Cape Coast Senior High Schools and that of day girls will be higher'.

Table 6: HFZ Performance Analysis of Fitnessgram Measurement of Muscular Strength (Modified Push-ups) Test

\begin{tabular}{|l|l|l|l|l|l|}
\hline HFZ & Range & \multicolumn{2}{l|}{ Day Girls } & \multicolumn{2}{l|}{ Boarding Girls } \\
\hline & & $\mathrm{n}$ & $\%$ & $\mathrm{n}$ & $\%$ \\
\hline High performance & $36-44$ & 0 & 0 & 3 & 3 \\
\hline Good fitness zone & $30-35$ & 4 & 10 & 5 & 4 \\
\hline Marginal & $23-24$ & 32 & 80 & 82 & 68 \\
\hline Need improvement & $17-22$ & 4 & 10 & 30 & 25 \\
\hline Total & & 40 & 100 & 120 & 100 \\
\hline
\end{tabular}

Table 6 below depicts the data on the modified push-ups used as the basis to determine the muscular strength of the respondents. It is evident from the table that the day students are fitter in muscular strength than their boarding counterparts.

The decision is buttressed by the percentage scores of the respondents as shown in Table 6 .

Comparatively, about $90 \%$ of the day students are within the marginal zone and above, (that is, 36 out of 40 were able to do 23 and more of the push-ups), while only $75 \%$ of the boarders were successful.

Again, while about $25 \%$ of the boarders performed poorly and therefore needed improvement in muscular strength buildup, only $10 \%$ of their day colleagues were in need. This situation could be attributed to the fact that most of the day students are engaged in routine vigorous bulk of activities such as washing of their clothing and that of family relations, cooking, weeding, which are not allowed or performed in the boarding set up.

This goes to answer research question 3 and confirms and accept sub-hypothesis 3 that the day girls are stronger in muscular strength than their boarding counterparts. However, the high performance of the boarding girls at the marginal zone could be explained by the menial activities such as washing, lifting of 
trunks and other pieces of luggage, carrying of books while climbing and descending of the hills in the two schools.

In addition, good and variety of meals could contribute to the advantage that the day girls have over the boarders. While the boarders are restricted to pantry menus, day girls are exposed to a number of foods which they have the option to select from, according to their purchasing power. Some of the boarders, in an attempt to meet their hunger, after refusing the kitchen food, either due to monotonous or total dislike, will settle for gari, sugar, Milo and Water mixture, which is neither nutritious nor balanced. According to Ulrich (2006) proper nutrition is important to physical fitness, because energy expenditure depends on nutrition. If diet is inadequate, the fitness level will drop. Overweight, underweight and weak individuals will have below average strength fitness level.

Sub-question 4: What is the difference in Flexibility levels between day and boarding SHS girls in Cape Coast

The 'Sit-and Reach' test was used to determine the flexibility of the respondents. Subjects were made to go through the process in turns and the results recorded as presented in Tables 7 and 8 below.

Table 7: Independent Samples t-test Result of Flexibility (sit-and-reach). Test for Day and Boarding Girls

\begin{tabular}{|l|l|l|l|l|l|l|l|}
\hline Group & $\mathrm{N}$ & $\mathrm{M}$ & SD & SE & df & T & Sig. \\
\hline Day & 40 & 38.93 & 5.08 & 0.80 & 158 & 5.66 & $0.00(\mathrm{~S})$ \\
\hline Boarders & 120 & 32.58 & 8.66 & 0.79 & & & \\
\hline
\end{tabular}

As the calculated t-statistics in Table 7 above depicts, it is clear that at 5\% level of significance there is no evidence in these data to reject the alternative or sub-hypothesis 4 . This is indicative of the fact that with tstatistic value of 5.66, the p-value (0.00) is less than the 0.05. Again, comparing the means throws more light on the conclusion reached. With 38.93 and 32.58 for day and boarding girls respectively, it is clear evidence that at $5 \%$ confidence level the day girls are more flexible than the boarders. This is further substantiated by the data in Table 8 .

Table 8: HFZ Performance Analysis of Fitnessgram Measurement of Flexibility (Sit-an

\begin{tabular}{|l|l|l|l|l|l|}
\hline HFZ & Range & \multicolumn{2}{l|}{ Day Girls } & \multicolumn{2}{l|}{ Boarding Girls } \\
\hline & & N & $\%$ & N & $\%$ \\
\hline High performance & $\begin{array}{l}38 \text { and } \\
\text { above }\end{array}$ & 24 & 60 & 39 & 33 \\
\hline Good fitness zone & $34-37$ & 14 & 35 & 35 & 29 \\
\hline Marginal & $29-36$ & 2 & 5 & 16 & 13 \\
\hline Need improvement & Below 28 & 0 & 0 & 30 & 25 \\
\hline Total & & 40 & 100 & 120 & 100 \\
\hline
\end{tabular}

A cursory view of the data in Table 6 indicates that whilst as much as $95 \%$ of the day girls fell within the Good-Fitness-Zone and above, only $62 \%$ of the boarders challenged them. The situation became even clearer when $25 \%$ of the boarding girls were so rigid that they could not do more than 28 of the flexibility test repeatedly, as against the $0.0 \%$ of the day students. The differences could be explained by the vigorous daily activities that the day girls go through as routine at home. Activities such sweeping, washing and 
cleaning of all types of things, walking briskly to and from school and involvement in indoor and outdoor games both in school and at home render the day girls more flexible than their boarding counterparts. The boarders on the other hand do not engage in any strenuous activity while on campus. Most of the vigorous activities are done by the first years. This result is supported by the previous findings of Miller (1994) that active people are more flexible than inactive individuals.

\section{Sub-question 5: What is the difference in Body Composition Fitness levels between day and boarding SHS girls in Cape Coast?}

To test for significant differences in the body composition of the two groups of subjects, the independent sample t-test statistic and the HFZ percentage attainment techniques were used and the results presented in Tables 9, 10, and 11 below.

Table 9: Independent Samples t-test Result on Day and Boarding Girls Body Composition (Skin fold)

\begin{tabular}{|l|l|l|l|l|l|l|l|}
\hline Group & $\mathrm{N}$ & $\mathrm{M}$ & $\mathrm{SD}$ & $\mathrm{SE}$ & $\mathrm{df}$ & $\mathrm{t}$ & Sig. \\
\hline Day & 40 & 36.45 & 5.25 & 0.83 & 158 & -5.53 & $0.00(\mathrm{~S})$ \\
\hline Boarders & 120 & 42.76 & 8.57 & 0.78 & & & \\
\hline $\mathrm{P}<.05$ & $\mathrm{~S}-$ Significant
\end{tabular}

The results as presented in Table 9 indicate marginal but statistically significant differences in the body composition of the two groups. The means, that is, 36.45 and 42.76 for day and boarding girls respectively show a close body composition but health wise it is in favour of the day students. This is because a higher mean in this wise means a higher percentage of body fats deposits which is a warning or basis for the contraction of many diseases.

From Table 9 above, as the p-value is less than 0.05 , we can statistically conclude that, at $5 \%$ level of significance there is enough evidence to accept sub-hypothesis 5 that, 'there is a significant difference in body composition fitness levels between day and boarding girls in Cape Coast Senior High Schools.

Table 10: HFZ Performance Analysis of Fitnessgram Measurement of Body Fat (Skin Fold) of Subjects

\begin{tabular}{|l|l|l|l|l|}
\hline HFZ & \multicolumn{2}{|l|}{ Day Girls } & \multicolumn{2}{l|}{ Boarding Girls } \\
\hline & $\mathrm{n}$ & $\%$ & $\mathrm{n}$ & $\%$ \\
\hline Low & 0 & 0 & 0 & 0 \\
\hline Good fitness zone & 36 & 90 & 94 & 78 \\
\hline Marginal & 3 & 7 & 18 & 15 \\
\hline Obese & 1 & 3 & 8 & 7 \\
\hline Total & & & & 100 \\
\hline
\end{tabular}

Table 10 showing the HFZ performance analysis of measurement of body fat and BMI respectively further accentuate the results as depicted and discussed in respect of Table 9.

From table 10 the majority of the girls in both groups were found in the Good Fitness Zone. The situation is however not the same at the bottom whereas much as $26(22 \%)$ of the boarders were either marginally or terminally obese as much only $4(10 \%)$ of their day counterparts. This condition is not pleasant to the health of these young girls at all. The data in Table 11 below emphasizes this analysis very well. 
As clearly shown in the table 10 , about $75 \%$ of the day girls exhibited normal body condition as against the $68 \%$ of the boarders. These two figures indicate and confirm the good health condition that majority of the members of the two groups had, though that of the day students were better. This condition could be attributed to some of the daily manual strenuous activities that these girls go through which burns out most of fats or whatever they consume. According to the United State of American's Surgeon General's Report (2000), strength training will increase your lean muscle mass, which results in an accelerated metabolism.

Again, a troubling high number of the boarding girls sampled (about 22\%) were declared according to the research findings as either overweight or obese as against the $10 \%$ of the day students. This condition is very detrimental to the health of the girls at the boarding school.

Table 11: Independent Samples t-test Result of Body Composition (BMI) on Day and Boarding Girls

\begin{tabular}{|c|c|c|c|c|c|c|c|}
\hline Group & $\mathrm{N}$ & $\mathrm{M}$ & SD & SE & $\mathrm{df}$ & $\mathrm{t}$ & Sig. \\
\hline Day & 40 & 34.46 & 5.25 & 0.84 & 158 & -5.43 & $0.00(\mathrm{~S})$ \\
\hline Boarders & 120 & 40.71 & 7.52 & 0.76 & & & \\
\hline
\end{tabular}

Table 11 above depicts the t-test result on the Body Composition (BMI) of the students. The evidence affirms the sub-hypothesis that the fitness level pertaining to the day students is higher than that of the boarders. With a comparatively lower mean level of 34.46 of the day students as against 40.71. This conclusion is further confirmed with the HFZ Performance Analysis of Fitnessgram Measurement of BMI of subjects in Table 12.

Table 12: HFZ Performance Analysis of Fitnessgram Measurement of BMI of Subjects

\begin{tabular}{|l|l|l|l|l|l|}
\hline HFZ & Range & \multicolumn{2}{l|}{ Day Girls } & \multicolumn{2}{l|}{ Boarding Girls } \\
\hline & & $\mathrm{n}$ & $\%$ & $\mathrm{n}$ & $\%$ \\
\hline Underweight & Below 18.9 & 5 & 13 & 12 & 10 \\
\hline Normal & $19-24.9$ & 30 & 75 & 82 & 68 \\
\hline Overweight & $25-29.9$ & 3 & 7 & 17 & 14 \\
\hline Obese & $30-40$ & 2 & 5 & 9 & 8 \\
\hline Total & & 40 & 100 & 120 & 100 \\
\hline
\end{tabular}

The difference in body fat deposition could be a result of a number of factors but environment had not been identified as one. However, heredity, glandular disorders, ageing and basal metabolic rates (BMR) have been mentioned as contributing agents (Corbin et al. 2003).

The daily shuttling of the day girls between the school and the house, and other activities were active to burn most of the food or calories which might be stored as fats. According to Prentice (1999), numerous studies have shown that walking can be a very effective component of a weight loss program. It is beneficial and ranks high compared to other popular forms of exercises.

\section{Conclusions}

From the HFZ values and the t-test statistical results, the boarding girls are weaker in respect of fitness in cardiovascular endurance, muscular endurance, muscular strength, flexibility and body composition. This condition is not at all healthy and needs an urgent, practical and comprehensive approach to solve it. 
All the subjects were young and need not have had any marked difficulty in going through the test items used for the research. For example, at their ages they should not be incapable of stretching far enough forward due to the fact that they have soft tissues (ligaments, tendons) of the joints, as well as the muscles. The inability to stretch far forward indicates tightness in the low back and hamstrings due to inactivity (Lidell, 1997). Heidelberg (1996) also supports the fact that tight hamstrings limit lower back flexibility which results in back pain.

\section{References}

[1] Akorsah, B. (2006). Talking point. Ghana Television.

[2] Boateng, K. F. (2006). Rising heart diseases at Korle-Bu, GTV Interview. .

[3] Bucher, C. A., \& Prentice, W. (1985). Fitness for college and life St. Louis.

[4] Corbin, C. B., Linsey, R., Welk, G. L., \& Corbin, W. R. (2002). Concept of fitness and wellness $\left(4^{\text {th }}\right.$ ed). Chicago: McGraw-Hill Companies Inc.

[5] David, N. (1986). The sports medicine fitness course. New York: Bull Pub. Co.

[6] Fahey, T. D., Insel, P. M., \& Roth, W. T. (2002). Fit and well. A edition. (5 ${ }^{\text {th }}$ ed). Dubuque: McGraw Hill.

[7] Heidelberg, A. (1996). Guidelines for promoting physical activity among older persons. (www.who.int/hpr/heidelberg_eng.pdf). Geneva, 25 ${ }^{\text {th }}$ August 2007.

[8] Insel, P. M., \& Roth, W. T. (2002). Fit and well. Alternate edition (4 ${ }^{\text {th }}$ ed) Dubuque: McGraw Hill.

[9] Laliberte, R. (2001). Activity for physical fitness, retrieved, April 10, 2007 www.Nutritionaustralia.org/FoodFacts/Facts/FAQ/PhysicalFitness.

[10] Lidell, L. (1997). The sensual body. New York: Simon and Schuster, Inc.

[11] Lindsey, R., Welk, G. I., \& Corbin, C. B. (2000). Concept of physical fitness. Dubuque: Brown and Benchmark.

[12] Lindsey, D. T., Insel, P. M., \& Roth, W. T. (2002). Core concepts and labs in physical fitness and wellness. Alternate edition, Dubuque: Brown \& Benchmark. McGraw Hill Higher Education.

[13] Miller, D. K. (1994). Measurement by the physical educator. Dubuque, C. Brown Comm Inc.

[14] Prentice, W. E., (1994). Fitness for college and life ( ${ }^{\text {th }}$ ed) New York: WM.C. Brown Publishers.

[15] Prentice, W. E. (1999). Fitness and wellness ( $6^{\text {th }}$ ed). Dubuque: WCB McGraw Hill.

[16] Prudential Fitnessgram, (2002). Prudential fitnessgram. The Institute for Aerobic Research in Dallas, USA.

[17] Ulrich, C. (2006). Physical fitness. Retrieved, September 14, Microsoft Encarta Encyclopedia 2006 version.

[18] United States of America's Surgeon General's Report (2000). The physiological benefits of $\begin{array}{lllll}\text { exercising } & \text { regularly. } & \text { Retrieved, } & \text { November } & 10,\end{array}$ www.cyberparent.com/fitness/healthfitness/defines/healthy1.htm.

[19] WHO (2008). Regional office for Europe. Retrieved may 14, 2008. (http://www.euro.who.int/hepa/20050708_5).

[20] World Health Organization, (Guidelines Series for Healthy living, No. 1, accessed 18 March 2002). Retrieved June 2007 